\title{
OPVOEDKUNDIGE TEGNOLOGIE REKENAARONDERSTEUNDE ONDERRIG
IN DIE WEERMAG
}

Dr D. L. Hattingh*

The South African Institute for Educational Research was requested by International Business Machines to conduct an experiment at the Department of Cataloguing and Codification of the South African Defence Force with computer-assisted instruction. Although the experiment did not conform to all scientific standards it did nevertheless show that it is feasible to use computer-assisted instruction.

\section{INLEIDING, PROBLEEMSTEL- LING EN METODE}

Op 25 Oktober 1974 het International Business Machines (IBM) die Raad vir Geesteswetenskaplike Navorsing (RGN) versoek om die moontlikheid van ' $n$ eksperiment met rekenaarondersteunde onderrig te bespreek. Van die samesprekings wat uit hierdie versoek voortgespruit het, het die RGN die moontlikheid gunstig oorweeg en op 11 November 1974 het IBM 'n skriftelike versoek in dié verband aan die RGN gerig. IBM het onder andere die volgende in hulle brief vermeld:

'Die SAW se Direktoraat Kodifisering en Katalogisering kan onmiddellik voorsien in al die basiese elemente vir so 'n aanvangsprojek $\mathrm{nl}$ ' $\mathrm{n}$ behoefte vir versnelde opleiding van groepe studente met ' $n$ reeds afgebakende gebied vir opleiding asook die rekenaarapparatuur en die beskikbaarheid daarvan.

Wat programmatuur betref, bestaan daar reeds verskeie produkte wat in so 'n projek gebruik kan word. As ons bydrae tot die projek sal ons graag ' $n$ stelselingenieur om met die versorging van die programmatuurkaart behulpsaam te wees, voorsien.

Ons stel voor dat ' $n$ vergadering van al die belanghebbende partye onder u leiding belê word sodat ' $n$ projek vir aanvang in Januarie 1975 uitgepluis en gedefinieer kan word.'

Op 2 Januarie 1975 het die RGN op die skrywe van IBM gereageer en 'n vergadering is belê vir 27 Januarie 1975, waartydens voorlopige, algemene riglyne neergelê sou word vir die uitvoering van hierdie ondersoek.

\section{PROBLeEMSTELLING}

Daar word reeds allerweë erken dat goeie indiensopleiding 'n aansienlike verbetering in die produktiwiteit van die werknemers van enige soort werkgewersinstansie meebring. Die probleem waarmee werkgewers van groot ondernemings wat oor rekenaars beskik egter gekonfronteer word, is die aangeleentheid van kosteeffektiewe onderrig. Laasgenoemde probleem geld veral tov instansies wat landswyd verspreid is, soos byvoorbeeld die Weermag en die Poswese. In die verlede het opleiding meestal volgens konvensionele metodes by verskillende takke of op 'n sentrale punt plaasgevind. Ten spyte van die welbekende voordele van konvensionele onderrig, is daar sekere nadele aan verbonde wat ' $n$ behoefte aan 'n alternatiewe opleidingsvorm skep.

Die volgende nadele van konvensionele onderrig is algemeen bekend:

(a) Aangesien werknemers dikwels 'n kursus by die hooftak moet volg, word reis- en verblyfkoste hoog.

(b) Implementering van die kennis van studente wat tydens 'n kursus opgedoen is, vind stadig plaas omdat studente groepsgewys opgelei moet word en vir die volle duur van die kursus, geen arbeid kan verrig nie.

(c) Werkskontinuilteit word benadeel deur onttrekking van personeel vir opleiding.

\section{PROBLEME MET DIE OPLEIDING IN DIE BASIESE KURSUS IN KODIFISERING}

Die Weermag se afdeling Katalogisering en 
Kodifisering voorsien dat die aanvraag vir opgeleide kodifiseerders in die toekoms in 'n besondere mate gaan toeneem en dat die afdeling nie meer in staat sal wees om die opleiding te behartig nie. Om die probleem te bekamp, moet gepoog word om die kodifikasiekursus te rekenariseer. Indien dit moontlik is, kan die geprogrammeerde kursusse wat grootskaalse opleiding in die hand sal werk, onder verskillende instansies oor die land versprei word, met aansienlike besparing in tyd en koste.

\section{DOELSTELlings}

Die doelstelling met die projek is om ' $n$ eksperiment te loods ten einde te bepaal of -

(a) daar bepaalde beheerbare faktore is wat van rekenaarondersteunde onderrig 'n geslaagde onderrigvorm kan maak, en waarvolgens sekere riglyne neergelê kan word vir algemene gebruik in soortgelyke kursusse.

(b) daar vergelykbare of beter resultate met rekenaarondersteunde onderrig as met konvensionele onderrig verkry kan word.

\section{METODE}

\section{Hipoteses}

Daar word van die veronderstelling uitgegaan dat indien vergelykbare of beter resultate met rekenaarondersteunde (RO0) onderrig verkry kan word as met konvensionele onderrig, dit die Weermag beter sal betaal om die rekenaar in te span vir opleidingsdoeleindes aangesien hulle reeds oor ' $n$ rekenaar en terminale vir die doel beskik. Die hipoteses waarvoor bewysvoering gesoek word, is dan eerstens, dat die rekenaar net so goed of beter as konvensionele onderwys gebruik kan word vir opleiding in sekere afdelings van die Weermag en tweedens, dat R00 sekere voordele inhou bo konvensionele onderrig ten opsigte van die onderrigtende gebeure self, naamlik 'n korter opleidingstydperk en 'n besondere wyse van individualisering.

\section{Bewysvoering}

'n Metode wat beide betroubaar en geldig is, sou dus gevind moet word om te bepaal of rekenaarondersteunde onderrig die konvensionele onderrig by Weermagopleidingsinstansies kan vervang en of R00 sekere voordele ten opsigte van die onderrigtende gebeure self inhou bo die konvensionele metode van onderrig in die
Weermag.

Gevolglik is besluit op ' $n$ empiriese metode, te wete 'n eksperiment met twee groepe studente. Die een groep, voortaan die eksperimentele groep genoem, sou onderrig met behulp van die rekenaar ontvang en die ander groep, voortaan die kontrolegroep genoem, sou volgens die bestaande metodes onderrig word. Aangesien 'n vergelyking tussen dié twee groepe se prestasies slegs segswaarde kan hê indien die groepe verstandelik min of meer dieselfde is, dit wil sê eweveel skrander en swak studente bevat wat afgepaar kan word, moes 'n stelsel vir afparing ontwerp word. Gevolglik is spesiale toetse afgeneem waarvolgens ' $n$ verdeling gemaak kon word. Ter onderskraging van die gebruik van toetse om ' $n$ verdeling moontlik te maak, is vraelyste ook aan die studente voorgelê om ingevul te word. Aan die einde van die kursus is die studente weer versoek om vraelyste in te vul, sodat vasgestel kon word of daar nie onbekende faktore is wat die resultate van die eksperiment nadelig kon beïnvloed nie. Studente van beide groepe sou 'n finale toets aflê onder dieselfde voorwaardes. Hierop sou 'n retensie- of geheuetoets volg om te bepaal of kennis meer blywend vasgelê word op dié metode wat gevolg is by die onderrig van die onderskeie groepe.

Aanvanklik is beplan om al die studente wat 'n kursus bywoon by die Direktoraat van Kodifisering en Katalogisering te gebruik as kontrolegroep en al die studente van ' $n$ volgende kursus as eksperimentele groep. Gevolglik is toetse afgeneem by studente wat ' $n$ kursus tydens 1975 bygewoon het, met die doel om daaruit studente te kies wat vergelykbaar sou wees met studente uit die eksperimentele groep ten opsigte van ouderdom, persoonlikheidseienskappe en IK. 'n Lid van die personeel van die RGN het dan ook die kursus bygewoon om eerstehandse kennis op te doen van die studente en die metodes van onderrig aldaar.

Aangesien daar tydens die voltooiing van die module vir die rekenaar nie genoeg terminale bekom kon word nie, is besluit om die kursusgangers van Julie 1977 in twee groepe te verdeel wat dan respektiewelik die eksperimentele en kontrolegroep sou uitmaak. Weens die beperkte getal studente kon afparing soos aanvanklik beplan, nie geskied nie en is die studente slegs volgens geskatte IK verdeel.

Om die leser op die hoogte te hou van moontlike faktore wat die homogeniteit van die twee groepe 
kon beïnvloed, word die resultate van die eerste toetse en vraelyste in afdeling twee en drie weergegee.

\section{VERDERE VERLOOP VAN DIE VERSLAG}

In die volgende afdeling word die aard van die konvensionele kursus bespreek waarop 'n afdeling gewy word aan die vrae wat studente van die konvensionele kursus beantwoord het. Vervolgens word die gerekenariseerde kursus bespreek en opgevolg met 'n bespreking van die eksperimentele fase.

\section{DIE KONVENSIONELE KURSUS}

\section{AARD VAN LEERSTOF}

Die kursus wat aan studente by die Direktoraat Katalogisering en Kodifisering aangebied word, word ' $n$ basiese kursus in Kodifisering genoem. Die doel met die kursus is om voornemende kodifiseerders op te lei in die identifisering en kodifisering van items wat in voorraad gehou of aangekoop moet word. Inligting in verband met items word volgens sekere voorskrifte op dokumente ingevul wat dan eventueel in die rekenaar gelees word. Met die stelsel word voorkom dat aankope gedupliseer word en kan 'n maklike kontrole uitgeoefen word oor beskikbare voorrade. Die stelsel vergemaklik ook die aanvraag en verspreiding van voorrade. Aangesien die stelsel soveel voordele inhou, veral in die noukeurigheid van identifisering van items, het verskeie instansies buite die Weermag soos byvoorbeeld Atlas, SAPPI en EVKOM by die stelsel ingeskakel. Gevolglik word die kursus nie slegs deur Weermaglede bygewoon nie.

Vir die doel van die eksperiment is een afdeling van die kursus naamlik 'Completion of Form 34' gerekenariseer. Vorm 34 word ingevul deur gebruikmaking van alfa-numeriese simbole wat 'n kenmerk, stand, metode, instansie of aktiwiteit voorstel.

Slegs alfa-numeriese kodes word op die vorm ingevul in ooreenstemming met voorskrifte wat in boekvorm aan die studente voorsien word. Hierdie vorms word dan gebruik om inligting op die rekenaar oor te dra.

Weens die eng en strak uitgestipte aard van die voorskrifte verg die kursus weinig kreatiewe denke. Tewens die kursus kan beskou word as een wat hoofsaaklik memoriseerwerk vereis.

\section{AANBIEDINGSWYSE}

Die kursus word aangebied by wyse van lesings wat opgevolg is met praktiese werk. Tydens die lesings word ryklik gebruik gemaak van aanskouingsmateriaal en swartbordsketse. Klasgesprekke het ook soms plaasgevind. Aanskouingsmateriaal was hoofsaaklik beperk tot voorrade-items.

\section{STUDENTE VAN DIE KURSUS}

Aangesien die tipe student wat die kursus bywoon ' $n$ invloed kan hê op die resultaat van die eksperiment, word 'n kort beskrywing van 'n groep studente gegee wat 'n kursus bygewoon het en wat vir alle praktiese doeleindes as tiperend van die kursusgangers beskou kan word. Ter verduideliking van die eersgenoemde stelling word verwys na talle eksperimente wat in oorsese lande gedoen is om vas te stel of sekere tipes studente meer baat vind by rekenaarondersteunde onderrig as andere. Volgens sekere navorsers kon verskille gevind word in die prestasies van studente wat verskil in temperament, intelligensie en ouderdom. Alhoewel daar geen aandag aan hierdie aspek gewy is in die onderhawige eksperiment nie, word die inligting verstrek vir diegene wat 'n volledige beeld wil hê van die opset van die eksperiment.

\section{AKADEMIESE KWALIFIKASIES, OUDER- DOM, MOEDERTAAL EN WERKGEWER}

\section{TABEL 1}

$\begin{array}{lll}\text { STUDENT } & \text { HOOGSTE KWALIFIKASIES } & \text { WERKGEWER } \\ 1 & \text { B.M.I. B.Com. } & \text { SAW (Leër) } \\ 2 & \text { B.A. Handel } & \text { SAW (Vloot) } \\ 3 & \text { St. } 10 \text { NTS III } & \text { SAW (Leër) } \\ 4 & \text { St. } 10 \text { (Eind) } & \text { SAW (Vloot) } \\ 5 & \text { St. } 10 \text { (Eind) } & \text { SAW (Leër) } \\ 6 & \text { NTS III St. 8 } & \text { EVKOM } \\ 7 & \text { Intermediate City of Guilds } & \text { EVKOM } \\ 8 & \text { St. } 8 \text { MECPI City \& Guilds } & \text { EVKOM } \\ 9 & \text { St. } 7 & \text { EVKOM } \\ 10 & \text { St. } 10 \text { (Eind) } & \text { SAW (Leër) } \\ 11 & \text { Skooleindeksamen Engeland } & \text { EVKOM } \\ & \text { City \& Guilds MECP } & \\ 12 & \text { St. } 10 \text { (Eind.) } & \text { SAW (Leër) } \\ 13 & \text { St. } 10 \text { (Eind.) } & \text { SAW (Leër) } \\ 14 & \text { St. } 10 \text { (Eind) } & \text { EVKOM } \\ 15 & \text { St. } 8 \text { NTS III } & \text { EVKOM } \\ 16 & \text { B.A. } & \text { SAW (Leër) } \\ 17 & \text { Tegniese skool (4 jaar) (Israel) } & \text { EVKOM } \\ 18 & \text { St. } 10 \text { (Eind.) } & \text { EVKOM }\end{array}$




\section{Geskatte IK van studente}

Die Instituut vir Psigometriese Navorsing van die RGN het toetse afgeneem en op grond van die toetse die volgende IK-syfers toegeken.

\section{TABEL 1}

$\begin{array}{lrlll}\text { STUDENT } & \text { IK } & \begin{array}{l}\text { OUDER- } \\ \text { DOM }\end{array} & \begin{array}{l}\text { MOEDER- } \\ \text { TAAL }\end{array} & \begin{array}{l}\text { STUDIE- } \\ \text { PROBLEME }\end{array} \\ 1 & 136 & 21 & \text { Afr. } & \text { Nee } \\ 2 & 126 & 30 & \text { Afr. } & \text { Nee } \\ 3 & 125 & 31 & \text { Afr. } & \text { Nee } \\ 4 & 125 & 42 & \text { Eng. } & \text { Nee } \\ 5 & 117 & 26 & \text { Afr. } & \text { Nee } \\ 6 & 105 & 32 & \text { Eng. } & \text { Ja } \\ 7 & 104 & 31 & \text { Eng. } & \text { Nee } \\ 8 & 103 & 24 & \text { Eng. } & \text { Ja } \\ 9 & 103 & 34 & \text { Eng. } & \text { Nee } \\ 10 & 102 & 22 & \text { Afr. } & \text { Nee } \\ 11 & 100 & 31 & \text { Eng. } & \text { Nee } \\ 12 & 91 & 47 & \text { Afr. } & \text { Nee } \\ 13 & 90- & 45 & \text { Afr. } & \text { Ja } \\ 14 & 90- & 54 & \text { Eng. } & \text { Nee } \\ 15 & 90- & 29 & \text { Afr. } & \text { Nee } \\ 16 & 90- & 55 & \text { Afr. } & \text { Nee } \\ 17 & 90- & 32 & \text { Hebreeus } & \text { Nee } \\ 18 & 90- & 37 & \text { Eng. } & \text { Ja }\end{array}$

('90-' beteken 'n IK laer as 90)

Volgens die toetsafnemers is die IK nie heeltemal betroubaar nie. Nietemin gee dit ' $n$ indikasie van die groot verskille in intellektuele vermoëns onder die geledere van die kursusgangers.

\section{Opmerkings}

Eind. is 'n afkorting vir eindeksamen en Afr. en Eng. vir Afrikaans en Engels onderskeidelik. Ouderdom is in jare aangedui en die studente het self op ' $n$ vraelys aangedui of hulle studieprobleme het al dan nie.

\section{DUUR VAN KURSUS}

Studente vanuit alle oorde word in Pretoria gehuisves vir ongeveer 6 weke. Gedurende hierdie tydperk moet hulle klasse bywoon vir 'n volle werksdag, elke dag van 'n werksweek. Lesings en praktiese werk word slegs onderbreek vir teepouses en die etensuur. Aan die einde van die opleidingsperiode word ' $n$ eksamen afgelê. Die laaste week word feitlik in sy geheel in beslag geneem deur praktiese werk.

\section{VRAELYSTE BEANTWOORD DEUR STU. DENTE WAT DIE KONVENSIONELE KURSUS VOLG}

Oor die algemeen wil dit nie voorkom of die studente die kursus besonder moeilik gevind het nie, terwyl uiteenlopende menings uitgespreek is oor die bruikbaarheid van die kursus.

\section{DIE GEREKENARISEERDE KURSUS}

\section{DIE ITS-STELSEL}

Die afkorting ITS staan vir 'Interactive Training System' en word so genoem omdat die student met dié stelsel direk met die rekenaar kan kommunikeer. Aangesien hierdie stelsel geen basiese rekenaartaalkennis van die outeur van 'n kursus verg nie, het die keuse daarop geval. Hierdie stelsel word deur IBM beskikbaar gestel en met 'n IBM-rekenaar gebruik.

\section{Implementering van die ITS-stelsel}

Verskeie vorms wat 'worksheets' genoem word, word deur IBM beskikbaar gestel. Hierdie 'worksheets' word deur die skrywer van die kursus ingevul in die ruimtes wat voorsien is en ook naas sekere kodes of sleutels sodat die lesse vanaf die 'worksheets' direk op die rekenaar, met behulp van 'n terminaal, ingelees kan word.

\section{Moontlikhede van die ITS-stelsel}

Aangesien hoofsaaklik van 'n 'Question Worksheet' gebruik gemaak is, word dit kortliks bespreek. Die 'Question Worksheet' maak voorsiening vir vier verwagte verkeerde antwoorde, twee onverwagte verkeerde antwoorde en twee versoeke om 'n leidraad vir die antwoord te gee. Vir elke moontlikheid kan die outeur kommentaar skryf wat die rekenaar dan aan die student lewer. ' $n$ Vraag word nie meer as drie keer herhaal nie. Indien die leerling herhaaldelik verkeerd antwoord, kan die rekenaar outomaties die regte antwoord verstrek. Voorsiening word ook gemaak vir vertakking uit 'n 'Question Worksheet'.

Met die ITS-stelsel is dit moontlik om verslag te hou van die getal pogings wat 'n student aanwend voordat hy ' $n$ vraag korrek beantwoord, asook van die getal verkeerde antwoorde wat hy gee. Aan die einde van 'n toetssessie word die student se persentasie outomaties aan hom verstrek. 


\section{AANBIEDINGSWYSE VAN DIE KURSUS VAN DIE WEERMAG MET DIE REKENAAR}

\section{Strategie}

Volgens die besluite op die vergadering van die Verkenningskomitee van 3 Februarie 1975 moes slegs een module opgestel word. Die keuse het op vorm 34 geval wat in sy geheel met behulp van die rekenaar aangebied moet word. Derhalwe is die strategie gekies wat sal voldoen aan 'n algehele plaasvervanging van die instrukteur naamlik 'aanbieding' (tutorial).

Die lesse het uit die volgende stappe of fases bestaan.

(a) Verduideliking of eksposisie van inhoud.

(b) Vraagstelling.

(c) Antwoordontleding.

(d) Wenke of kommentaar.

(e) Samevatting en hersiening.

In enkele gevalle is van vertakkinge gebruik gemaak en slegs vir daardie gevalle waar dit geblyk het dat die student nie die inhoud beheers nie. Remediëring het plaasgevind na die aflê van toetse op so 'n wyse dat slegs daardie dele van die leerstof waarop die studente foutief antwoord, hersien word. In laasgenoemde geval is vir sover moontlik, gebruik gemaak van antwoordontledings waarmee die presiese aard van die fout van die student uitgewys kon word. Tydens die beantwoording van die vrae, kan die studente te enige tyd wenke aanvra waardeur die probleem verder toegelig word sonder om die antwoord self te verkry. Wanneer die student vir die eerste keer hulp vra, word hy slegs in 'n geringe mate gehelp. By ' $n$ tweede versoek word hy met genoegsame leidrade vir die oplossing voorsien.

\section{Handleiding}

Elke student is gedurende die tydperk wat hy onderrig deur middel van die rekenaar ontvang het, van ' $n$ boekie voorsien met verduidelikende aantekeninge, diagramme en plate wat met 'n spesiale instrument gespeel kon word. Hierdie boekie is gebruik tydens die rekenaaraanbiedingsessies, maar kon ook deur die student tuis gebruik word. Die doel hiermee was om te voorkom dat die rekenaar hoofsaaklik gebruik word om teks weer te gee wat beide onekonomies en 'n onderbenutting van die moontlikhede van die rekenaar vir onderrigdoeleindes is. Sodoende is die rekenaar meestal gebruik vir daardie aspekte van die onderrig waar dit besliste voordele inhou bo ander vorme van onderrig, terwyl dié dele wat net sowel deur 'n ander media aangebied kan word in boekvorm of met behulp van plate aangebied is.

\section{Oudiovisuele aanbieding}

Aangesien verduideliking aan die hand van diagramme geskied, is dit goed gedink om van plaatopnames gebruik te maak sodat die student nie nodig het om sy oë van die diagramme af te haal terwyl verduideliking op die plaat gegee word nie. Die geskrewe teks was dan in elk geval nog as ekstra hulp tot sy beskikking indien die tempo van verduideliking op die plaat vir hom te vinnig was. Indien die student se geheue hom in die steek laat, kon die student met behulp van die geskrewe teks iets vinniger naslaan as met die stem op die plaat. Die studente het na die plate geluister met behulp van oorfone wat aan die apparaat wat die plate speel, gekoppel was.

\section{PROSEDURE BY DIE OPSTEL VAN PROGRAM}

\section{Logisering van leerstof}

Alle beskikbare literatuur in verband met kodifisering is geraadpleeg met die doel om die leerstof op so 'n wyse aan te bied dat dit kort en saaklik gestel kan word sonder om onduidelikheid en vaagheid in die hand te werk. Ten einde die nuwe teks te toets vir verkeerde interpretasies van die oorspronklike geskrifte, het die verantwoordelike persone by die Weermag alle teks nagegaan en in oorleg met die RGN, is sekere dele van die teks, hersien. Hierdie prosedure is gevolg ten opsigte van die teks vir die handleiding, die plaatopnames en die rekenaarprogram.

\section{Opstelling van draaiboek en verfilming}

'n Multi-media-aanbieding is verkies bo rekenaargeskrewe teks alleen sodat studente meer as een sintuig kan gebruik. Om hieraan te voldoen, is 'n draaiboek geskryf vir die maak van films en diagramme en die voorsiening van 'n klankbaan. Uitvoering is gegee aan die opdragte in die draaiboek deur bemiddeling van die Direktoraat Personeelontwikkeling van die Suid-Afrikaanse Weermag wat met die Produksiesentrum vir Opleidirggshulpmiddele van die Suid-Afrikaanse Vloot, geskakel het. Altesaam 86 diagramme is gemaak vir gebruik saam met plaatopnames wat in Duitsland vervaardig is. Die koste hiervoor is deur die Direktoraat Personeelontwikkeling ge- 
dra. Lede van die RGN het Simonstad besoek om regstellings by die verfilming en stemopname aan te bring.

\section{DIE EKSPERIMENT}

\section{SAMESTELLING VAN GROEPE}

Studente wat die Kodifikasie-kursus tydens die Juniekursus 1977 bygewoon het, is gekies vir die finale eksperiment. Sestien studente, is deur navorsers van die Instituut vir Psigometrika onderwerp aan toetse aan die hand waarvan hulle in twee groepe verdeel is. Die een groep bestaande uit 8 studente sou die kontrolegroep vorm en die ander 8 , die eksperimentele groep. Volgens die bekwaamheidstoetse waaruit 'n geskatte IK afgelei is, is die studente gerangskik van hoogste na laagste IK.

Aan elke student op die lys is ' $n$ nommer toegeken van 1 tot 16 . Die ongelyke nommers is gekies vir een groep en die gelyke nommers vir die ander groep. Sodoende kon twee vergelykbare groepe gevind word met min of meer vergelykbare studentepare uit elke groep. Die kontrolegroep het volgens konvensionele metodes onderrig oor vorm 34 ontvang terwyl die eksperimentele groep slegs rekenaarondersteunde onderrig daaroor ontvang het. Die studente is ook geleentheid gegee, om aan te dui of hulle bereid is om dmv die rekenaar onderrig te word. Op grond van die studente se aanduidings is ' $n$ enkele wysiging in die verdeling van die groepe aangebring. Weens siekte kon alleen die student met die hoogste IK in die eksperimentele groep nie die kursus bywoon nie. Al die ander studente van beide groepe kon die kursus voltooi.

\section{PLEK VAN EKSPERIMENT, TERMinALE EN TYDSDUUR}

Die Departement van Binnelandse Inkomste het toestemming verleen dat die eksperiment in die South African Eagle-gebou plaasvind. Vier terminale was in een lokaal beskikbaar en een in die rekenaarkamer. Die terminale wat die studente gebruik het, was IBM 3277 skermterminale.

Aangesien die terminale net saans na werkure beskikbaar was, het al die sessies in die aande plaasgevind. Slegs twee aande, met twee sessies elke aand, was nodig om die gerekenariseerde kursus te voltooi. Omdat daar nie genoeg terminale beskikbaar was om al die studente van die eksperimentele groep gelyktydig vir ' $n$ sessie te neem nie, is hulle weer in twee groepe van vier studente per groep verdeel. Geleentheid om die ekstra terminaal in die rekenaarlokaal te gebruik, is geskep vir 'n enkele student uit die tweede groep wat nie kans gesien het om laat te bly nie. Die eerste groep het om $19 \mathrm{~h} 00$ en die tweede groep om 21 hoo begin en albei het vir ongeveer twee ure gewerk.

Elke student het dus twee sessies van ongeveer twee uur aan die program gewy. Gedurende hierdie tyd is die onderrig in die voltooiing van vorm 34 afgehandel.

\section{VERGELYKING VAN TOETSRESULTATE}

\section{TABEL 4 \\ PUNTE BEHAAL IN FINALE TOETS

$\begin{array}{cc}\text { KONTROLE- } & \text { EKSPERIMENTELE } \\ \text { GROEP } & \text { GROEP }\end{array}$

\begin{tabular}{lcc} 
Student & Persentasie & Persentasie \\
$(1)$ & 100 & Afwesig \\
$(2)$ & 91 & 90 \\
$(3)$ & 81 & 90 \\
$(4)$ & 81 & 90 \\
$(5)$ & 72 & 90 \\
$(6)$ & 72 & 90 \\
$(7)$ & 72 & 61 \\
$(8)$ & 72 & 54 \\
TOTAAL & $\underline{541}$ & 565 \\
\hline
\end{tabular}

GEMIDDELDE PERSENTASIE

80

Uit die voorgaande tabel (tabel 4) kan afgelei word dat vir hierdie eksperiment rekenaarondersteunde onderrig, indien nie beter nie, minstens net sulke goeie resultate lewer as die konvensionele onderrig. Hierby moet in aanmerking geneem word dat die aantal studente wat vir die eksperiment gebruik is, besonder klein is en dat die resultate met groter groepe moontlik beduidend kon verskil het. Verder is dit nodig om daarop te wys dat die skranderste leerling van die eksperimentele groep afwesig was en die student wat die swakste presteer het in hierdie groep, weens sy hoë ouderdom probleme met sy sig gehad het. (Die letters wat op die terminale se skerms verskyn het, kon 'n persoon met swak oë strem in sy leesvermoë.) Desnieteenstaande die resultate moet die voordele wat rekenaaronderrig bo konvensionele onderrig inhou, in gedagte gehou word by evaluering van die rekenaarondersteunde onderrig in die Weermag. Immers, uit 'n bloot ekonomiese oogpunt, sou effens swakker 
resultate met rekenaarondersteunde onderrig moontlik nog verkieslik wees bo konvensionele onderrig.

$\mathrm{Na}$ verloop van minstens twee weke is 'n retensietoets op albei groepe uitgevoer. Presies dieselfde vrae, wat deur instrukteurs van die Weermag opgestel is, is aan beide groepe gevra. Dieselfde tydsbeperking is ook op albei groepe gelê.

TABEL 5

PUNTE BEHAAL IN RETENSIETOETS

$\begin{array}{cc}\text { KONTROLE- } & \text { EKSPERIMENTELE } \\ \text { GROEP } & \text { GROEP }\end{array}$

\begin{tabular}{|c|c|c|}
\hline Student & Punt & Punt \\
\hline 1 & $9 \frac{1}{2}$ & Afwesig \\
\hline 2 & $8 \frac{1}{2}$ & $8 \frac{1}{2}$ \\
\hline 3 & $7 \frac{1}{2}$ & 8 \\
\hline 4 & $7 \frac{1}{2}$ & 7 \\
\hline 5 & 6 & $6 \frac{1}{2}$ \\
\hline 6 & 3 & $5 \frac{1}{2}$ \\
\hline 7 & 3 & $5 \frac{1}{2}$ \\
\hline 8 & $2 \frac{1}{2}$ & 4 \\
\hline Totaal & $47 \frac{1}{2}$ & \\
\hline
\end{tabular}

GEMIDDELD

\section{6}

$6 \frac{1}{2}$

Ook die retensietoets het nie 'n beduidende verskil in die prestasie van die twee groepe getoon nie.

\section{VERGELYKING VAN TYD BESTEE AAN KURSUS}

Tydens die kursus van 1975 wat een van die lede van die RGN bygewoon het, is vier dae aan die onderrig in verband met die invul van vorm 34 bestee. Die eksperimentele groep wat in 1977 onderrig met behulp van die rekenaar ontvang het, het ongeveer vier uur aan dieselfde taak gewy. Geen tydkontrole is deur die RGN aangewend ten einde te bepaal presies hoeveel tyd die kontrolegroep aan dieselfde werk bestee het tydens die 1977-kursus nie.

\section{'N VERGELYKING VAN VRAELYSTE BE. ANTWOORD DEUR STUDENTE VAN DIE EKSPERIMENTELE EN KONTROLE- GROEP}

Van die sewe studente van die eksperimentele groep het slegs een die kursus wat met die rekenaar aangebied is, moeilik gevind. Dieselfde geld vir die studente van die kontrolegroep waar een student 'moeilik' geantwoord het vir sover dit die konvensionele kursus betref. Die student van die eksperimentele groep wat probleme met die kursus gehad het, voer sy hoë ouderdom (67 jaar) as rede aan.

Al die studente van die eksperimentele groep het die gerekenariseerde kursus interessant gevind. Een van die studente van die kontrolegroep het geantwoord dat die kursus oninteressant is.

Van die 15 studente wat die vraelyste beantwoord het, het drie die taalgebruik vir die volg van verduidelikings in verband met die invul van vorm 34 remmend gevind. Twee hiervan was in die eksperimentele groep en een in die kontrolegroep.

Oor die algemeen was die studente van beide groepe tevrede dat die handleiding volledig genoeg is. Met die uitsondering van drie wat aangedui het dat hulle nie weet nie, het al die studente te kenne gegee dat die handleiding duidelike uiteensettings gegee het. Ten opsigte van die handleiding wat gedurende die gerekenariseerde kursus gebruik is, het studente die volgende antwoorde gegee op 'n vraag hoe laasgenoemde handleiding vergelyk met die ander wat tydens die konvensionele kursus gebruik is.

$\begin{array}{ll}\text { Dieselfde } & 3 \text { studente } \\ \text { Beter } & 2 \text { studente } \\ \text { Swakker } & 1 \text { student } \\ \text { Ek weet nie } & 1 \text { student }\end{array}$

Ook in hierdie opsig blyk geen noemenswaardige verskille wat die resultate kon beïnvloed, te wees nie.

Aangesien al die studente van die eksperimentele groep ' $n$ gedeelte van hulle kursus volgens die konvensionele metodes van onderrig ontvang het, is aan hulle ook gevra op watter wyse hulle verkies om onderrig te word.

Vier studente verkies om onderrig met behulp van die rekenaar te ontvang, terwyl drie die konvensionele metode verkies. Van die vier studente wat rekenaarondersteunde onderrig verkies, het twee onder andere as rede(s) aangevoer dat hulle teen hulle eie tempo kon werk. Twee het aangedui dat die rekenaar geduldig is, twee dat die rekenaar hulle voortdurend vrae vra en een dat hersiening 
te enige tyd met die rekenaar gedoen kan word. Die vraag was so gestel dat studente meer as een rede kon aandui indien hulle so verkies.

Op 'n vraag of die studente van die eksperimentele groep enige probleme met die onderrig deur middel van die rekenaar ondervind het, het die meeste ontkennend geantwoord. Een van die studente is van mening dat dit te veel van 'n student gevra is om, nadat hy heeldag lesings bygewoon het, ook nog saans sy volle konsentrasie te gee.

Op die vraag of studente gemotiveer is vir die gerekenariseerde kursus het vier 'nee' en drie 'ja' geantwoord. Dit wil dus nie voorkom of die studente besondere hoë verwagtinge van die rekenaarkursus gekoester het nie. Hieruit kon afgelei word dat die sogenaamde nuutjie-effek nie ' $n$ besondere invloed op die studente tydens hierdie eksperiment gehad het nie. Die skynbare belangeloosheid by studente kan heel waarskynlik toegeskryf word aan 'n min of meer skeptiese houding teenoor rekenaarondersteunde onderrig by die instrukteurs van die Weermag. Aan die anderkant kan seker ook afgelei word dat die ingesteldheid van die instrukteurs die eksperiment nie die resultate beduidend negatief kon beïnvloed het nie (kyk Tabel 4).

Ten einde te bepaal of daar enige aspekte verbonde aan die gerekenariseerde kursus was wat besonder geslaagd is, is ' $n$ vraag in dié verband gestel. Aangesien studente meer as een van die aspekte kon aandui of hulle eie mening kon gee, word die antwoorde en die getal studente wat op elke antwoord gereageer het in 'n tabel weergegee.

\section{TABEL 6}

\section{ANTWOORD}

GETAL

Die baie voorbeelde

Vrae oor alle aspekte van die werk

Werk teen eie tempo

STUDENTE

ANDER

Duidelike uiteensettings

Totale getal studente

Vir vergelykingdoeleindes is ' $n$ aantal vrae aan studente van die kontrolegroep gevra om te bepaal of daar enige faktore was wat die resultate van die kursus nadelig kon beïnvloed. Uit die antwoorde blyk dat die onderrig wat hulle ontvang het nie afwyk van dié wat normaalweg by konvensionele onderrig in die Weermag aangetref word nie. Dit is dus wel moontlik om die resultate van die eksperimentele groep en die kontrolegroep in dié opsig te vergelyk en te veralgemeen. Die belangrikste moontlike beswaar vir doeleindes van veralgemening is die klein getal studente wat aan die eksperiment deelgeneem het.

\section{GeVOlgtrekKING eN AAN- BEVELING}

\section{FAKTORE WAT DIE GELDIGHEID VAN RESULTATE KON BEİNVLOED}

Die geldigheid van enige eksperiment van dié aard hang af van die mate waarin faktore wat 'n bepalende invloed uitoefen, uitgeken kan word en van die mate van kontrole wat oor die faktore uitgeoefen kan word. Dikwels speel sodanige onbekende of onbeheersde faktore so 'n groot rol dat eindresultate misleidend kan wees. Dit is dan die eerste taak van die wetenskaplike om die moontlike invloed van sodanige faktore noukeurig na te gaan en in sy veralgemenings die uiterste versigtigheid aan die ag te lê. Met die onderhawige eksperiment is dit dan ook die geval dat etlike moontlike faktore uitgewys kan word wat die eindresultaat kon beïnvloed.

(a) Eerstens het konvensionele aanbieding en toetsing van die kandidate heeltemal buite die kontrole van die RGN gestaan.

(b) Aangesien terminale en 'n rekenaar nie beskikbaar was nie, moes 'n buite-instansie genader word en kon die lesings met behulp van die rekenaar slegs saans aangebied word. Gevolglik is 2 uur-sessies aangebied wat volgens die bevindings van oorsese navorsers heeltemal te lank is.

Hierbenewens het studente vir die volle dag lesings bygewoon voordat hulle saans geleentheid gekry het om met die rekenaar onderrig te word.

(c) Die aard van die leerstof is sodanig dat dit die moontlikhede van die rekenaar beperk het.

(d) Die studentegroepe was so heterogeen dat dit haas onmoontlik is om korrelasies te soek tussen persoonlikheidseienskappe en gesindhede teenoor rekenaarondersteunde onderrig. 
Die belangrikste beswaar teen die eksperiment wat moontlik deur wetenskaplikes geopper sou kon word, is die klein getalle waarmee die eksperiment uitgevoer is. Vir meer bevredigende resultate sou dit wenslik wees dat so 'n eksperiment herhaaldelik uitgevoer word en dat baie meer studente by die eksperiment betrek word. Om hierdie redes is dit ook nie moontlik om statistiese ontledings te maak wat betekenisvol sou wees nie.

\section{DIE BETEKENIS VAN DIE EKSPERI- MENT}

Ten spyte van al die moontlike besware ten opsigte van die geldigheid van die eksperimente kan seker met vrymoedigheid beweer word dat nie uit die eksperiment afgelei kan word, dat rekenaarondersteunde onderrig onsuksesvol is nie. Immers, alle aanduidings wys daarop dat dit lonend sal wees om verder te eksperimenteer, veral met die doel om eksperimenteelgewys, metodes sodanig te verbeter dat definitiewe riglyne neergelê kan word vir die toekomstige implementering van rekenaarondersteunde onderrig (R00).

Uit die toetsresultate, ceteris paribus, kan die gevolgtrekking gemaak word dat R0O 'n plaasvervanger vir groepsonderwys wat by ' $n$ bepaalde plek gegee word, kan wees. Indien met 'n rekenaarprogram dieselfde resultate bereik kan word as met konvensionele onderrig, soos blyk uit die eksperiment, en die reeds genoemde voordele van ROO in ag genome, kan beweer word dat daar sin in is om met R00-eksperimente voort te gaan.

\footnotetext{
Dr D. L. Hattingh is verbonde aan die Suid-Afrikaanse Instituut vir Opvoedkundige Tegnologie.
} 